[82:81'38]:821.111(71).09-31 Bala S.

7.038.6:821.111(71).09-31 Bala S.

316.75(71): 821.111(71).09-31 Bala S.

https://doi.org/10.18485/asec_sacs.2021.9.ch12

\author{
Sanja Ignjatović \\ University of Niš, Serbia \\ Bogdan Stankovic ${ }^{* *}$ \\ University of Niš, Serbia

\section{THE POSTPOSTMODERN REFUGEES, MIGRANTS AND CANADIANS IN SHARON BALA'S THE BOAT PEOPLE}

\begin{abstract}
The paper explores the political, ideological and social moment of Sharon Bala's debut novel The Boat People (2018) by contrasting different perspectives on personal and collective identity, with the view of answering the question of whether the novel belongs to the so-called post-postmodern poetics: a trend emerging from or evolving within the broader poetics of postmodernism. What the paper specifically focuses on is the manner in which the novel is narrated, the choice of focalizing subjects and the unsettling open-end, quite appropriate considering the relevance of the issues dealt with, all of which situate Sharon Bala's debut novel in a very specific category of literature that grants voices to those who are otherwise exploited for the endorsement of political and other agendas. Bala's characters' personal narratives reflect on Canadian multiculturalism and its intricacies, racism, xenophobia, and fundamental human needs.
\end{abstract}

\title{
Keywords
}

post-postmodernism, postmodernism, Canadian literature, personal identity, national identity, contemporary Canadian novel, The Boat People.

\footnotetext{
*sania.ignjatovic@gmail.com

**stbogi95@gmail.com
} 


\section{Introduction}

The critical interpretation of Sharon Bala's novel, The Boat People (2018) starts with an examination of the theoretical basis of postmodern poetics and the still vague, yet present in contemporary literary and art criticism, the poetics of metamodernism. In other words, the Introduction to this paper presents an attempt to clarify how metamodernism is defined, and then answer whether contemporary literature could be influenced by this new poetics to the extent of it requiring its own theoretical framework; or whether metamodernism is a trend or practice that can satisfactorily be explained in terms of postmodern poetics and its expected and inevitable evolution. The Discussion section will illustrate, on the example of the mentioned contemporary novel by Sharon Bala, how contemporary literature interprets culture, social and political circumstance. That is, the analysis of the narrative techniques employed, the rhetorical strategies and intentions, the metafictional nature of the novel, as well as its temporal and spatial setting will produce a basis for assessing the poetics of the work. In the Conclusion, we propose that the trend called 'metamodernism' is not a poetics encompassing the vast body of contemporary literature (and art), but an attempt at creating a new theoretical frame in spite of practice.

In After Theory (2003), Terry Eagleton presents some of his paramount arguments in favor of literary Theory, but also against postmodernism (and postmodern art). Eagleton claims that "[i]f theory means a reasonably systematic reflection on our guiding assumptions, it remains as indispensable as ever" (Eagleton 2003: 2), emphasizing negatively that its course towards skepticism, the rejection of "universal values, grand historical narratives, solid foundations to human existence and the possibility of objective knowledge" (Eagleton 2003: 13) does not present grounds for progress and unity (a modernist viewpoint, no doubt), but a movement towards "cultural relativism," "pluralism," "discontinuity and heterogeneity" (Eagleton 2003: 13). Eagleton's romantic view of the normative, and his reluctance to perceive its artificial unifying power - to homogenize as opposed to the postmodern rejection of universal values - leads him to a conclusion that:

The postmodern cult of the migrant, which sometimes succeeds in making migrants sound even more enviable than rock stars, is a good deal supercilious in this respect. It is a hangover from the modernist cult of the exile, the Satanic artist who scorns the suburban masses and plucks an elitist virtue out of his enforced dispossession (Eagleton 2003: 21).

Eagleton's disdain for the postmodern artist, the cultural migrant - the pastiche of a person that refuses to abide by a tradition - seems to be precisely what Sharon Bala in The Boat People examines through a variety of characters. Eagleton's resentment focuses on the postmodern rejection of the concept of 
established tradition and norm, and ironically, it is in this rejection that Eagleton sees the political catastrophe. Without the normative, it seems, Eagleton sees no possibility of political unity and consensus. And yet, the normative appears to be loosely defined and vaguely situated in the past, in the modernist fashion. In Encyclopedia of Postmodernism, Taylor and Winquist comment on modernism as "[i]ronically, [achieving] its goal of determining art's essential nature by establishing that it had no intrinsic qualities and that its critical criteria were ideologically rather than historically determined (Taylor \& Winquist 2001: 18). Similarly to Taylor and Winquist, in A Poetics of Postmodernism (2004), Linda Hutcheon implies that a denunciation of hierarchy in terms of theory and practice is to be rejected and that this is precisely what postmodern art achieves, at least in theory by encouraging an aesthetic practice that is both "didactic and self-conscious" (Hutcheon 2004: 53). Hutcheon, among many others, of course, recognizes modernist roots in postmodern poetics in terms of its rejection of "classical realism", its rhetorical and representational techniques. However, Hutcheon also notices that Terry Eagleton's understanding of modernist "contradictions", and his insistence of them granting significant advantages over postmodernism in terms of, as the authors of this paper understand, pure Theory, relies on a dogma specifically challenged by postmodernism in terms of life and art being two separate and autonomous entities, as well as Theory being separate from art as a (purely) aesthetic dimension (Hutcheon 2004: 43). For Hutcheon, postmodern art implies an inseparable relation between 'life and art', and therefore Theory and its practice must be understood as co-extensive.

Moreover, whereas modernist ideology and technique internalizes contradictions, postmodernism thrives on their foregrounding either through rhetorical emphasis on 'little narratives' or their juxtaposition to the corrupt and obsolete mainstream discourse. The postmodern artist does not simply reject 'Truth' or the truth, but rather seeks it beyond what is represented as uniform state of affairs. Basically, postmodern art relates those voices which are either absent from the mainstream discourse, or those voices whose position in the world and respective discourses (social, political or economic) are identifiable in terms of contrast, against the mass culture discourses. What defines 'truth', Hutcheon says, is "the local, the limited, the provisional" (Hutcheon 2004: 43), and:

[p]aradoxically uses and abuses the conventions of both realism and modernism, and does so in order to challenge their transparency, in order to prevent glossing over the contradictions that make the postmodern what it is: historical and metafictional, contextual and self-reflexive, ever aware of its status as discourse, as a human construct. (Hutcheon 2004: 53)

In a society ruled by digital media and the Internet, it is almost naive to talk about postmodern art as anything but a "problematizing force" (Hutcheon 2004: $\mathrm{xi}$ ), in relation to both its theoretical postulates and artistic practices, and this 
claim, made by Linda Hutcheon at the very end of the twentieth century, has never been as relevant. On the one hand, immersed in information-consumerist and truth-relative culture, a culture in which the political discourses worldwide relativize the value of human life in terms of Western freedom, democracy and prosperity, postmodern art is the only remaining mode of critique available to humanize the individual otherwise perceived as statistical data. On the other hand, postmodern art remains on the margins of political action, imperceptible precisely because it faithfully emanates the voices it relates and suffers their fate. As Hutcheon notices, "postmodernism is always double-voiced inits attempts to historicize and conceptualize the enunciative situation of its art" (Hutcheon 2004: 44) - art that seemingly toys with modernist conventions precisely because its didactic purpose lies in the foregrounding of contradictions:

[...] the metalinguistic contradiction of being inside and outside, complicitous and distanced, inscribing and contesting its own provisional formulations [...] To move from the desire and expectation of sure and single meaning to a recognition of the value of differences and even contradictions might be a tentative first step to accepting responsibility for both art and theory as signifying processes. In other words, maybe we could begin to study the implications of both our making and our making sense of our culture. (Hutcheon 2004: 21)

Sharon Bala's novel The Boat People, essentially a series of narratives converging in the present moment Canada, is a novel whose fragmented formal structure and spatio-temporal shifts render it somewhat historiographic. The storyline follows a group of migrants - emigrants, immigrants or terrorists, depending on the perspective, and the members of the legal team aiding in their hearings, but also those deciding on their cases' outcomes, trapped in a bureaucratic loop upon their arrival in Canada. Their cases are presented in courts and their fates are decided on the basis of their ability to reconstruct their own narratives against the political climate of Canada, and reinvent themselves in hopeless, homeless and desperate situations, hindered by unlucky circumstance, linguistic and cultural barriers. Sharon Bala's novel ends without the much awaited catharsis of denouement, however, it is precisely its open end that inspires a postmodern reading. In other words, rhetorically speaking, it is its open end that invites the reader to provide an interpretation, however unsettling, unsatisfying or disappointing it may turn out to be. The question that arises from the openend concept of Bala's novel is directed at the implied reader. Quoting Margaret Atwood's claim that universal literature does not truly exist because there are no "truly universal readers" (quoted in Hutcheon 2012: xi) seems appropriate for Bala's The Boat People which appears aimed not only at the particular kind of reader, but a very specific society.

In The Canadian Postmodern (1988), Linda Hutcheon notices that "postmodernism would designate art forms that are fundamentally self-reflexive - in other 
words, art that is self-consciously art (or artifice), literature that is openly aware of the fact that it is written and read as part of a particular culture, having as much to do with the literary past as with the social present" (Hutcheon 2012: 2 ), and the self-reflexive nature of Bala's novel is not only visible in terms of the author's possible biographical or autobiographical intrusion, but also in the manner in which characters' narratives are structured to provide voices for those whose social inclusion or assimilation seems to be both implied and celebrated as part of Canadian multiculturalism while the historical peculiarities or un-pleasantries remain obscure. In 1988, when The Canadian Postmodern was first published, Linda Hutcheon examines the contemporary Canadian novel and notices that:

In their self-reflexivity, Canadian postmodern novels offer yet another example of the self-conscious or 'meta-' sensibility of our times, that is, of the awareness that all our systems of understanding are deliberate and historically specific human constructs (not natural and eternal givens), with all the limitations and strengths which that definition entails. (Hutcheon 2012: x)

It is precisely this sensibility and the artificial nature of history that Sharon Bala explores in The Boat People, along with the nature of the narratives we live by, and our personal narratives - narratives shaped by history as we are made to perceive it, by social, political and ideological interactions. Following the tradition of many other Canadian authors whose metafiction or historiographic (meta)fiction relies on the readers' moral and political sense, Sharon Bala explores the concept of history, personal history and narrative, cultural identity and norm, as well as what it is that could be termed 'truth' - the controversial postmodern concern, or rather the realization that "[T]ruth has been replaced by truths, uncapitalized and in the plural" (Hutcheon 2012: viii-ix). Following this line of thought, Chantal Pontbriand's witty take on history may shed more light on why the past stands as postmodernism's inevitable (or rather, irreplaceable) vantage point - history may be explained as "a vast theatre in which a drama is unfolding, that of representation, or of art itself" (Pontbriand 1987: 51), and Bala's characters' 'dramas' unfold precisely in that fashion - they both struggle with the 'appropriate' representation of their own pasts, and their 'new identities' - the Canadian versions of themselves, although Canada, for most of them, remains only a vague image, a fantasized destination that, at least in the novel, never manifests.

In his study Onto the Postcontemporary (2013), two decades or so during which Linda Hutcheon's seminal work, The Canadian Postmodern, has seen many a new edition, Peter Brooks comments on the general state of contemporary Canadian literature and notices that postmodern art "is always too busy, tracing its own heritage, assimilating the past into its own image, and reformulating how it can remain relevant" (2013: x). In the case of The Boat People, this 
necessity to regurgitate the past, decide its relevance and use in the present moment retains broader implications. Sharon Bala's novel not only opens the door to an investigation of the past that resonates a personal quest, that of the author herself perhaps, but also involves the reader in the process of political, ideological and, ultimately, cultural decision re-making. In saying that postmodern art is "always too busy", too burdened, perhaps, by the past, Brooks offers a view on postmodern art, or literature in this case, as wedged between the past and present, impotently - removed from the possibility of reaching meaning and drawing onto the past for what seems to be lacking in the present. In Brooks' view, contemporary Canadian literature moves in a direction that seems to be less burdened by heritage, or less obsessed with adding a piece to the Canadian national-identity puzzle; and more directed at its own transformation and transformative vision, to put it succinctly. Debatable as it may be, for postmodern contradictions and eccentricities thrive on both the presence and absence of the past, Brooks' insight remains relevant for the topic of this paper, as a source of inspiration, but also in terms of pointing the authors of this paper to look more closely into those aspects of postmodernism that have been transformed or appropriated by contemporary literature, and termed, especially in the last decade, among other things, metamodern.

The theoretical groundwork for what is called metamodernism bases itself mostly on the work of The Metamodernist Manifesto and Vermeulen and van den Akker's critical revisions of architecture and art in general. In Criticism and Metamodernism (2014), they see a change in the postmodern paradigm, one "[i]n stark contrast with the art of the 1990s, which tended to be characterized by irony, cynicism and deconstruction, contemporary practices are often discussed in terms of affection, sincerity and hopefulness (Vermeulen \& van den Akker 2014). These critics' view on contemporary art, and therefore literature, is focused on its refusal to conform to postmodern instruments. In the same article, they quote a renowned New York art critic, Jerry Saltz, to summarize the core values of contemporary art:

[the] genus of cynical art that is mainly about gamesmanship, work that is coolly ironic, simply cool, ironic about being ironic, or mainly commenting on art that comments on other art" has become less popular. There is a new attitude that says I know that the art I'm creating may seem silly, even stupid, or that it might have been done before, but that doesn't mean this isn't serious. (Vermeulen \& van den Akker 2014)

Vermeulen and van den Akker speak about "an end to postmodernism" in terms of a transformation of the general (or popular) artistic or creative paradigm (2014), but they also seem to suggest that the transformations take multiple forms in different fields. The authors of the paper notice an ironic streak in their determination to replace old terminology based on the necessity to reformulate 
theory that would explain the proliferate practice. It is precisely change and transformation that are inherent in postmodern art, and it should be no wonder that they produce a multiplicity of forms and expressions, even if these regress or reflect originally on the present moment. These authors suggest that what needs to be established is "a sense of how we may begin to think theoretically beyond the parameters we were taught in history classes in art schools and universities; a modality that allows us to align our concepts with the intuitions so many of us seem to share" (Vermeulen \& van den Akker 2014), but the question that comes to mind then is what kind of theory would be sufficient or advanced enough to "make sense of these changes" (Vermeulen \& van den Akker 2014) if not the theory of postmodern art. In fact, the nature of theory Vermeulen and van den Akker are striving to establish is quite questionable and does not resonate at all with postmodern substance. In a sense, their suggestion resonates with Terry Eagleton's rejection of postmodern multiplicity and indeterminacy for it offers no definite solutions to the human condition. They suggest that:

Contemporary practices $[\ldots]$ would no longer contribute to our understanding of art's essence, but instead demonstrate that there is no essence, or if there is, that it allows for an eternally expansive variety of forms, methods and concepts. Art is free from all restraints. Today, after all, everything can be art: aBrillo box, a can of soup, a toilet bowl, a turd. But it doesn't take a visionary to see that artists today are still very much concerned with Bildung, with imagining alternative narratives, communities and systems of rule and exchange. Further, to suggest that pluralism and freedom are one and the same thing carries in it a misunderstanding of freedom. The pluralism of the 1960s and 1970s merely operated under other kinds of restrictions, just as the Romanticism and Classicism Danto discusses, too, functioned under alternative constraints. It is possible that art will diversify even more the next few years, but it is also imaginable that it will become more specific. Whatever its course, we should not simply assume that it has played its part-in terms of affinity, identity, spirituality or otherwise-in our development; it has simply changed its appearance. (Vermeulen \& van den Akker 2014)

Essentially, then, it is unclear what the theory of metamodern art, or metamodernism in general, should stand for. If the aspiration of metamodernism is to explain the essence of at, it should first and foremost understand the essence of the creative impulse produced in contemporary society, under contemporary conditions and socio-political and historical influences. On the one hand, Vermeulen and van den Akker see postmodern art too unconstrained or too loosely defined, and desire a more structured approach to contemporary aesthetics, but on the other, they do not recognize the elitist undertones in their proposition.

This paper argues that contemporary literature, and specifically Canadian, is still heavily influenced by postmodernism, but that there are also significant chang- 
es in the manner in which the postmodern tradition permeates contemporary literature. However, the argument here is that the postmodern presents a set of instruments for "problematizing" culture, ideology and politics (Hutcheon)-it is a specific kind of expression, assumption, technique, approach and design (formally, structurally and discourse-wise), and not merely a work of literature satiated with pastiche, irony and parody, as it is often derogatively described. The premise is that contemporary literature has not felt the need to look for its problematizing instruments further than in the postmodern tradition for it is postmodernism that essentially provides the most effective tools for examining contemporary culture, its fragmented narratives and neo-liberal capitalist ideology, and its "doubled discourse" and "cross-genre transgressions," as Aritha van Herk would phrase it in the Introduction to the Wynford Edition of The Canadian Postmodern (Hutcheon 2012). Therefore, the objective of postmodern techniques is to "democratize and make accessible information" (Hutcheon 2012) sourced from a de-centered position - a position which inevitably defamiliarizes and subverts the values of mainstream discourses.

\section{Discussion}

In discussing the postmodern in Sharon Bala' The Boat People, the paper focuses on the concepts such as community, multiculturalism, personal and collective identity in order to explicate the manner in which the author of the novel subverts these socially and politically colored concepts, and, at the same time, exposes them for the hypocrisy they represent in the twenty-first century Canada, in the context of the novel. Surely, a more poignant effect of this contemporary novel is indirectly achieved by the mere fact that the Sri Lankan refugees from The Boat People metaphorically stand for all of the displaced and dispossessed worldwide, welcomed by the Western nations, both in Europe and in the United States and Canada, as terrorists and economic migrants, undeserving of a chance of a normal life in a country not stricken by war, famine and unrest. Ultimately, Bala's message, particularly since it is one of a second-generation immigrant, is that of a society that, powered by nationalism and racism, relativizes human life.

In the Encyclopedia of Postmodernism, Taylor and Winquist offer the following definition of the concept of community:

At first glance, the word community signifies those elements that are held in common among people. However, postmodernism has been more interested in marking the negative aspects of community; specifically how community does not mark commonality but difference, and in its most negative sense. Instead of examining community in terms of inclusion, it examines it in terms of exclusion, not to valorize this state of things, but to mark its existence. (Taylor \& Winquist 2001: 58) 
This definition adequately describes the postmodern attitude towards community in terms of The Boat People where Sharon Bala juxtaposes the perspectives of the white Canadians, or those simply unburdened with different ethnic, cultural or racial background; and the perspectives of immigrants who, either instinctively or consciously, appropriate the practices and performatives of the majority in fear of being perceived as different. Moreover, the question of inclusion and exclusion as defined by Taylor and Winquist, and as narrativized by Bala in the novel, permeates the characters' actions, behavior and language, and suggests that the 'grand' narrative of multiculturalism, even in Canada, functions with inbuilt cultural and political limitations.

The events depicted in the novel take place between 2002 and 2009 in Canada and Sri Lanka, and the novel opens in medias res, when a cargo ship carrying approximately five hundred illegal Sri Lankan immigrants is intercepted just off the coast of Canada. The novel is features three narratives that, together, help the reader piece together the picture behind Mahindan, a Sri Lankan immigrant who arrives in Canada with his six-year-old son, Sellian; Priya, a young lawyer of Sri Lankan origin who is given the duty to accompany one of the lawyers who represent the immigrants during their admission hearings; and Grace, Japanese by origin, an adjudicator who is supposed to evaluate the testimonies of the immigrants and decide on the admissibility. The three narratives heavily intertwine, but also thread-away into independent narratives essentially dealing with the political and cultural limitations, imposed or self-imposed, in the quest for one's own identity as an immigrant. In a more general sense, these narratives, both pertaining to the past and the present, question the definition of the concept of community, national identity and personal identity.

The novel opens with Mahindan's experience of the voyage to Canada, and the difficulties of merely withstanding the claustrophobic and over-crowded cabins of a ship, especially after being subjected to the atrocities of war. His six-year old son is taken from him upon reaching Canada, and the separation leaves Mahindan retraumatized after witnessing death and suffering, but also after having his wife die during childbirth due to the lack of medical equipment in their war-stricken homeland. Aside from the obvious political problems and the danger that force him to board a ship to Canada, Mahindan is heavily burdened by guilt, and the guilt is at least two-fold and haunting. He is a mechanic, who was forced by the rebel army of Sri Lanka (The Tamil Tigers) to work on fixing a bus that would later be used in a suicide bombing, killing seventeen civilians, a proof of his problematic, potentially terrorist past, used against him during the hearings in Canada adjured by Grace. Beside being forced to help the Tamil Tigers, Mahindan also engages in what he would later on shamefully recall as unforgivable - selling identification papers taken from corpses and presenting them to others like him, those trying to escape the civil war, as the only possi- 
ble solution for reaching Canada. Justifiable in terms of his struggle to survive and reach a safe haven where his son would have a chance at a normal life, Mahindan does place people in danger and one of those people eventually commits suicide, which Mahindan witnesses. This character's intentions, inspired by self-preservation and fatherly love, fueled by optimism and the promise of Canada, remain complex - almost effortlessly justifiable at first glance, yet punishable in the eyes of the Canadian law and his own mind's eye:

I can trust Canada. (Bala 2018: 26)

It is precisely the lack of understanding for the complexity of both motives and circumstance, and the blatant disregard for his basic human rights, that gradually lead Mahindan into an apathy and disillusionment with Canada. It is during the absurdly lengthy admissibility hearings that he realizes that the expectations of those Canadians deciding on his fate, and their laws, do not empathize with the human situation, but merely human behavior idealized and romanticized. After releasing his son to a foster family that was supposed to take care of him, and the boy becoming "mysterious" and "wholly inaccessible" (Bala 2018: 329), Mahindan realizes that he is not only punished for surviving the civil war, but that his son too would be traumatized by yet another separation. The mention of the boy's grandparents being blown to pieces, and the atrocities of war he witnesses throughout their struggle to flee the country only add up to the realization that our 'civilized' minds are not attuned to the intricacies of the human situation - empathy becomes a commodity Mahidan cannot be granted for he neither paints the perfect picture of a war-refugee, nor is he recognized for a victim of war-persecution. Mahindan's endless admissibility hearings, and their not being resolved one way or the other, and the novel ending right before the supposed final hearing, suggest a contemporary Kafkaesque situation. Eventually, for the disenchanted and deeply depressed Mahindan, the promised land, and his personal piece of it - the prison cell - becomes a place "where they made the water to fall inside, where they drew a straight line between right actions and wrong" (Bala 2018: 327), and this vision seems to project that of the author, Sharon Bala, who elaborates it through the character of Grace's demented mother, and the insecure Priya.

Priya, a second-generation Sri Lankan immigrant, initially strives to be as Canadian as possible, and succeeds in her work without being discriminated against based on the color of her skin, or her ethnic background. Unlike other second-generation Sri Lankan immigrants in the novel, she consciously and ambitiously emulates the desired behavior of a Canadian, appropriating mannerisms, clothing style and consciously, or unconsciously, refusing to speak her mother tongue. The images of Priya at the opening of the novel only accentuate the changes she goes through by the end of it. Within the first pages of her nar- 
rative, her dissatisfaction at the racial profiling done by a partner in the law firm she works at, the transfer from corporate law to an immigrant case, suggests almost some sort of anxiety. Priya is nearly offended at how anyone would correctly identify her as Sri Lankan, or imply she would have any deeper relations with that culture - being Canadian. Her imposter syndrome kicks-in, and her Canadian identity is reshuffled as she is forced to witness the ordeals the boat people go through, and understand that it could have easily been her in any of their places because of the race, culture and ethnic identity. The experience, and the interaction with fellow Sri Lankans incite a change in Priya's perception of both Canadian and Sri Lankan culture. The character gradually sheds layers of doubt, guilt and fear about her position in the Canadian society, the law firm and her family, and begins to accept her origins as a source of empowerment and connection with her late mother, her family, and the extended family that the immigrants become. She grows more sympathetic towards the situation of the boat people in general after her uncle reveals a long-kept secret about his involvement with the Tamil Tigers, and she begins to comprehend that the singular, black-and-white, truth as sought by the law cannot hold: "We thought it would be a short term struggle," her uncle confesses, retelling a disturbing account of the situation that forced him to flee the country and explaining his motives to enlist in the first place:"One, two years maximum, and Sri Lanka would let us have our own country" (Bala 2018: 270). The imposter-Priya who barely speaks the language transforms into "Priya Auntie" (Bala 2018: 315) and discovers an entirely novel dimension of her life in Canada.

Grace, the third-generation Japanese immigrant, fully integrated into the Canadian society and its institutions, a public servant of sorts, perceives the immigrant situation in a very clear, black-and-white way. Inexperienced, she is appointed to the position of the adjudicator by the minister of public safety, Fred Blair, the embodiment of the mistreatment of immigrants and the negative attitude towards them in the Canadian society - the closest thing to a tangible antagonist the novel has to offer. It is no coincidence (even though the author claims otherwise in her note) that Fred Blaire has the same name as his predecessor, infamous for his strict policies against the immigration of Jewish people from Nazi Germany prior to and during the Second World War. Grace is torn between two influences throughout the novel - Fred, who places his trust in her and encourages her to be as strict as possible to the immigrants as "they have ulterior motives" (Bala 2018: 321), thus posing potential threats to Canada; and her mother, who constantly reminds her of the turbulent history of their life in Canada and the segregation and mistreatment, urging her not to be subdued by revisionist or amnesiac narratives of multiculturalism and unity. In one of the conversations, Grace's mother, Kumi, barely lucid yet more conscious of the presence of the past in the present, exposes Grace as the perpetrator of a nationalist and fascist system that persecutes refugees under the guise of war on terror: 
I know what your job is, Kumi said. Making history... history... making it happen. And happen. Again. Again.

This is totally different! These people are... we're fighting a war on terror.

Yes, yes. War is always the excuse. Real war, fake war. Either will do. (Bala 2018: 325)

The three narratives have a dual function as they present the reader with the perspectives of people with various degrees of integration into the Canadian society, and provide an insight into how the perception and empathy of people who at one point emigrate to Canada, integrate and appropriate the mannerisms of the majority, become deviated and distorted, rendering fragile the construct of multiculturalism that breaks under the weight of a crisis. The characters of Mahindan, as a first-generation immigrant, Priya as a second-generation immigrant, and Grace, a third-generation immigrant, all provide multifaceted profiles of people who undergo transformations in order to establish themselves in the target society (or societies), and these transformations are as complex as those of the boat people. Bala ultimately suggests that the more integrated the immigrant becomes, the more likely it is for that individual to distance themselves from the problems that befall these contemporary refugees and immigrants precisely because they internalize the cultural, and political, tendency to view another not as a human being, but as the Other. The Canadian society, as described by Bala, the society that takes pride in its multiculturalism, in practice actually employs tactics to present differences as dangerous, and therefore alienates and excludes refugees. The linguistic peculiarity is not superficial but indicative of the power of the political discourse - the other is labeled a threat and their potential guilt is manifested in their treatment and endless Kafkaesque hearings. The character of Fred Blair epitomizes this political and cultural force that is translated into the government policies and legal practice, the public opinion, the treatment of the Other in the press, etc. which are all discriminatory, dehumanizing, and racist:

We will protect our borders from thugs and foreign criminals and those who seek to abuse our generosity. (Bala 2018: 46)

The multicultural Canada that Bala presents in the novel is a divided society, with nationalists, on the one hand, labeling refugees as "foreign criminals" and abusers of Canadian "generosity"; those who blindly reproduce the same mode of thinking by following example and perpetuating, voluntarily and involuntarily violence and injustice out of fear that their lifestyle and standard would be endangered; and those who perceive the viciousness of such campaigns, but who are either unable to act, or whose actions seem to drown in bureaucracy and policies. 
This is a test, Fred said. One false move on our part and we'll be inundated with freeloaders. (Bala 2018: 77)

The threat perceived by Blair, the fear incepted in Grace - the obedient public servant - resonates with what Kumi, Grace's mother, calls "fake war" (Bala 2018: 325). This instrument of deterrent, supposedly used to fight terror, functions in the same manner as terrorism as it takes innocent victims and instills irrational fear. Whereas Mahindan realizes his position being the perceived threat, and Priya starts to accept that there exist nuances in one's guilt or innocence, Grace remains somewhat closed off to the warnings of her mother, and some of her colleagues, that making mistakes in such cases may be too costly, and ultimately detrimental not only to the one making them, but to society as well. Benedict Anderson defines a nation as "an imagined political community" (Anderson, 1983: 143). This definition can especially be applied to a country founded by immigrants, and established by denying an ethnic group their basic human rights. Although former colonies, such as Canada, the United States, and Australia, de jure support and propagate multiculturalism as a national policy, there are clear signs that this is not applied de facto - which is precisely the problem the novel criticizes, as well as the blending into the collective identity, and hiding behind the national mask. The three degrees of integration into the $\mathrm{Ca}-$ nadian society that are observed through the thoughts and actions of Mahindan, Priya, and Grace actually show how the moral compass distorts under the effect of belonging to a common narrative, in this new world of "glossy, gleaming things" (Bala 2018: 86).The shift in the view towards the refugees is nothing more than an identification of the personal identity with the identity-narrative of the group. This begins as a wish to be accepted in the new community, but as shown in the novel, grows into an apprehension towards the "newcomers" and even hostility. Bala points out this distortion with the conflicting thoughts Grace experiences:

If your great-grandfather hadn't gotten on that ship a century ago, none of us would be here.

She thought briefly of the Tamil ship, then pushed it away. This was different. (Bala 2018: 89)

In Dispossession: The Performative in the Political (2013), Athena Athanasiou defines dispossession as referring to "processes and ideologies by which persons are disowned and abjected by normative and normalizing powers that define cultural intelligibility and that regulate the distribution of vulnerability (Butler \& Athanasiou 2013: 2). In The Boat People, Bala addresses the issue of dispossession most poignantly through the character of Grace's mother - a woman virtually stuck in a moment dating back to her childhood when, along with her close family, she was forced to a relocation camp for the Japanese. 
Her fragmented memories of the period coincide and parallel the protagonist's storyline, and especially the narrative of his life in Sri Lanka. The dispossession and her diminishing mental capacity are constantly juxtaposed to illustrate, interchangeably metaphorically and literally, how the society selectively remembers or forgets dismal acts and normalizes violence. The Japanese first, second and third generation immigrants' storyline is intertwined both with the protagonist's storyline and the storyline of another Sri Lankan family (first and second generation immigrants), all of whom, in their respective ways, struggle to make sense of the fragmented past or present - the inability to fully grasp the culture that surrounds them, or fully express their own cultural heritage due to self-censure. Athanasiou notes that dispossession is "a condition painfully imposed by the normative and normalizing violence that determines the terms of subjectivity, survival, and livability" (Butler \& Athanasiou 2013: 2), and it need not only refer to the Sri Lankan emigrants in the case of The Boat People, but also the Japanese, and to an extent, the Sri Lankan family where the imposition of the norm was embraced and obediently followed for fear of persecution, extradition, or simply not fitting in. This is precisely the reason why Grace sees the Tamil ship as "different", and the refugees' stories as "different" than her own - a powerful, socially, culturally and politically reinforced delusion.

\section{Conclusion}

Finally, to go back to the question of whether metamodernism presents a singular trend in contemporary literature, we need to reflect on whether, in practice, it has developed any authentic, unique or original instruments and forms. In those terms, it is rather difficult to categorize contemporary literature, or at least Bala's The Boat People, as 'metamodern' even if the design of the work or its overall message stray from the typical postmodern method. In fact, contemporary literature readily uses postmodern techniques, but it is the Theory that aspires to move away from the postmodern legacy. Furthermore, it may be argued that the metamodern movement, the discussion behind its yet disarrayed theoretical framework, presents a natural, even artistic response within the larger framework of postmodernism and postmodernity. Metamodern insistence on the sincere rather than sarcastic, the refusal of irony and parody as effective instruments of social, political and ideological critique, the favorizing of the intertextual to the supposed postmodern 'pastiche', etc., all suggest an exhaustion of ideas, rather than a creation of an entirely novel Theory and practice. In theory, the metamodern artist refuses to acknowledge the seemingly defeatist position that the postmodern practice implies, and rises from the ashes of the ideological wastelands of deconstruction to announce to the world that the individual has persevered and that optimism has come back, knocking on our twenty-first-century bolted doors to inspire both political action (activism) and social change. 
But, has not postmodern art been doing the same in practice (if not theory)? Postmodern literature has produced volumes on those unheard voices, the oppressed and the invisible, and established their presence in a larger context. Contemporary literature cannot be forced into optimism that is not genuinely felt, nor should new poetics be artificially produced to guide the creative impulse towards social change. If vision is what postmodern art lacks, then it is a crisis that cannot be fixed by merely proclaiming a new set of descriptive (yet obviously elitist prescriptive) values.

Sharon Bala's novel illustrates how contemporary literature uses postmodern techniques to implicate the reader and therefore invite them to take individual political action, but it does not make the novel any less postmodern or more metamodern. In Encyclopedia of Postmodernism, Taylor and Winquist say that "[c]losure of the book is a critique of totality and fixed meaning associated with the declaration of the death of the author. [...] an important declaration in postmodernity that coincides with both the death of the author and a rethinking of the traditional conception of meaning in Western thought (2001: 52). Bala's The Boat People resist closure, granted, but as Linda Hutcheon notices "postmodernism is fundamentally contradictory, resolutely historical, and inescapably political" (Hutcheon 2004: 4), and the overall message of Bala's poignant account of the treatment of those most endangered and exposed sets us into the beginning of the twentieth century. If the proponents of this new theory that is to explain the essence of contemporary art see it as remedial that all art should uniformly turn to positivist psychology, then that theory would be an unsupportable construct. "[a]ll repairs are human constructs", Linda Hutcheon argues, "both comforting and compulsory", but "postmodernist interrogations of humanist certainties live within this kind of contradiction" (Hutcheon 2004: 7).

\section{WORKS CITED}

Bala, Sharon. The Boat People. Anchor Books, 2018.

Brooks, Christopher, ed. Beyond Postmodernism: Onto the Postcontemporary. Cambridge Scholars Publishing. 2013.

Butler, Judith. Athanasiou, Athena. Dispossession: The Performative in the Political. Bodmin, Cornwall: Polity, 2013.

Eagleton, Terry. After Theory. Basic Books, 2003.

Hutcheon, Linda. A Poetics of Postmodernism. New York and London: Routledge: Taylor \& Francis Group, 2004. 
Hutcheon, Linda. The Canadian Postmodern - Study of Contemporary Canadian Fiction. Don Mills, Ontario: Oxford University Press, 2012. (First published in 1988)

Pontbriand, Chantal. "The Historical Factor: A Fundamental Theme in Canadian Contemporary Art." Parachute. Vol. 47. 1987.

Taylor, Victor. Winquist, Charles (Eds). Encyclopedia of Postmodernism. Routledge, 2001.

Vermeulen, Timotheus \&Robin van den Akker. "Art Criticism and Metamodernism." Artpulse,vol. 19, iss. 3, (2014), pp. 22-27URL: http://artpulsemagazine.com/ art-criticism-and-metamodernism 